\title{
A CONSTRUÇÃO DA AUTONOMIA NAS AULAS DE EDUCAÇÃO FíSICA: APLICAÇÃO E AVALIAÇÃO DE UMA PROPOSTA PEDAGÓGICA
}

\author{
Flaviana Fellegger Molina \\ Universidade Nove de Julho, São Paulo, São Paulo, Brasil \\ Elisabete dos Santos Freire \\ Universidade São Judas Tadeu, São Paulo, São Paulo, Brasil \\ Maria Luiza de Jesus Miranda \\ Universidade São Judas Tadeu, São Paulo, São Paulo, Brasil
}

\begin{abstract}
Resumo
O objetivo deste estudo foi analisar a aplicação de uma proposta pedagógica para estimular a autonomia nas aulas de Educação Física e identificar a perspectiva de uma professora e de seus estudantes sobre a proposta aplicada. Foram utilizados como instrumentos a observação, o questionário e a entrevista. A proposta aplicada estimulou a reflexão, a compreensão crítica e a competência dialógica dos estudantes. Entretanto, foram percebidas algumas dificuldades enfrentadas pela professora, como o controle de sua ansiedade, a tendência ao autoritarismo e a construção de expectativas irreais. Além disso, a avaliação do envolvimento do estudante precisa ser aperfeiçoada. Novas pesquisas podem contribuir para compreender a origem e as formas de superar as dificuldades identificadas.
\end{abstract}

Palavras-chave: Educação Física e Treinamento. Autonomia. Valores sociais.

\section{INTRODUÇÃO}

A presença de conflitos entre os estudantes tem levado muitos professores de Educação Física a elaborar projetos pedagógicos com o objetivo de estimular a formação de valores e melhorar o relacionamento entre os alunos. Para atingir este objetivo, por vezes são adotadas metodologias pautadas na heteronomia, seja pela imposição de punições àqueles que descumprem uma norma, seja pela premiação dos estudantes que adotam as atitudes desejadas. Desta forma, são construídas relações baseadas no respeito unilateral (LA TAILLE, 2006), que não permitem o debate sobre as normas e a conscientização do estudante sobre a possibilidade de que elas sejam questionadas. Recompensa e punição são práticas comuns na escola, que priorizam a doutrinação moral e, deste modo, não contribuem para a autonomia do educando (PARO, 2011).

Nas últimas décadas, houve um crescimento no número de estudos que analisam a construção da autonomia, resultando em grande discussão sobre o significado do termo (BENSON, 2007). Entretanto, como argumenta Paro (2011), embora o tema seja debatido intensamente, ainda não tem sido tratado de forma consistente na escola. Para Freire (2004) o indivíduo autônomo é aquele que conhece sua própria realidade, entende a responsabilidade de seus atos e, reconhecendo a presença do outro, toma suas próprias decisões, com liberdade. 
O autor argumenta que a escola e o educador devem auxiliar o estudante na transição entre a heteronomia e a autonomia, oferecendo espaço para que ele possa exercer seu papel nas escolhas coletivas e avalia-las.

Nessa perspectiva, para que a Educação Física possa contribuir para a construção da autonomia dos estudantes as práticas pedagógicas elaboradas não podem se basear em negociatas, prêmios ou castigos. Será necessário criar situações de aprendizagem fundamentadas no respeito mútuo, que permitam compartilhar o poder e a responsabilidade pelas escolhas. Para isso, o professor deve compreender o papel que do estudante desempenha neste processo. Como afirma Paro (2011, p. 199)

[...] não se trata tão somente de dar ou negar autonomia. Autonomia, a exemplo do que acontece com a educação, é algo que deve ser desenvolvido com a autoria do próprio sujeito que se faz autônomo. Isso acarreta implicações imediatas para a forma mesmo de realizar-se o processo ensino-aprendizagem. (itálico no original)

A construção de propostas para a formação de indivíduos autônomos nas aulas de Educação Física não é preocupação recente. Durante a década de 1970, Hellison propôs um programa para o ensino da Responsabilidade Social e Pessoal - TPSR, a partir do esporte (HELLISON; WALSH, 2002; HELLISON, 2003; CABALLERO-BLANCO; DELGADONOGUEIRA; ESCARTÍ-CARBONELL, 2013). Este modelo adota como princípio o respeito à "individualidade, potencialidade, opiniões e competência para tomar decisões de cada participante do programa" (HELLISON; WALSH, 2002, p. 292).

Assim, é possível perceber que no TPSR a autonomia é um valor fundamental (CABALLERO-BLANCO; DELGADO-NOGUEIRA; ESCARTÍ-CARBONELL， 2013). Hellison (2003) defende o "empoderamento" do estudante, possibilitado pela transferência paulatina de poder do educador para os participantes do programa. $\mathrm{O}$ autor propõe cinco metas para orientar a realização das aulas. São elas: respeito aos direitos e sentimentos dos outros, esforço, auto governo, auxílio aos outros e liderança.

A busca pela autonomia do estudante também pode ser percebida no programa Sport Education (SE), que reserva lugar especial para a construção de valores. SE foi proposto por Siedentop durante a década de 1980, com a intenção de tornar o esporte uma prática educacional (O'DONOVAN; MACPHAILB; KIRK, 2010; SIEDENTOP, 2002). Dessa forma, o trabalho com o esporte deve ser adaptado para possibilitar a participação de todos os alunos (SIEDENTOP, 2002).

Entre os objetivos propostos estão: conhecer o esporte e suas regras, participar de forma competente de atividades esportivas, valorizar a cultura esportiva e identificar as diferenças entre práticas esportivas consideradas boas ou más. Na proposta de Siedentop (2002), é possível identificar atenção à autonomia, à medida em que o autor enfatiza a necessidade de que os próprios estudantes ocupem papéis de responsabilidade ao planejar e gerir os eventos esportivos realizados (O'DONOVAN; MACPHAIL; KIRK, 2010; SIEDENTOP, 2002). Além disso, na perspectiva de Kirk (2006), a valorização do fair play e da igualdade, preconizada no programa, é mais uma forma de promover a emancipação dos estudantes.

TPSR e SE, assim como outros programas concebidos com a intenção de estimular a formação de valores, têm sido aplicados e avaliados nas últimas décadas (HELLISON; WALSH, 2002; HELLISON, 2003; VIDONI; WARD, 2009; O'DONOVAN; MACPHAIL; KIRK, 2010). Embora alguns resultados positivos tenham sido identificados (BAILEY et al. 
2009; WALSH; OZAETA; WRIGHT, 2010), eles ainda são inconsistentes (JONES, 2005; CAMIRÉ; TRUDEL, 2010).

No Brasil, as pesquisas que analisam as influências da Educação Física na autonomia dos alunos não têm atraído muitos estudiosos. Orientados pelo referencial do construtivismo, Leitão et al. (2011) investigaram as contribuições de jogos e atividades lúdicas para o desenvolvimento da autonomia moral e verificaram que é possível criar oportunidade para que exercitar a tomada de decisões sobre, por exemplo, a constituição das equipes e a adaptação nas regras.

É importante ressaltar que muitos fatores podem interferir nos resultados dos programas aplicados. Para Jones (2005) fatores externos às aulas de Educação Física, como a ética do esporte profissional, podem influenciar mais os alunos que as atividades propostas pelos professores. Outros elementos, como a metodologia utilizada, a conduta do professor (JONES, 2005) e os conflitos existentes entre integrantes da equipe escolar (CAMIRÉ; TRUDEL; BERNARD, 2013) também podem ter grande impacto no sucesso obtido.

Diante da complexidade envolvida na aplicação de programas voltados para a formação de valores, torna-se evidente a necessidade de ampliar o número de estudos qualitativos sobre o tema (FREIRE; MIRANDA, 2014). Na tentativa de contribuir para a ampliação do conhecimento sobre a relação entre Educação Física e valores, realizamos o presente estudo com os objetivos de (a) analisar a aplicação de uma proposta pedagógica para estimular a autonomia nas aulas de Educação Física e (b) identificar a perspectiva de uma professora e de seus estudantes sobre a proposta aplicada.

\section{MÉTODO}

Para atingir os objetivos propostos neste estudo foi conduzida uma pesquisa qualitativa, procurando olhar o fenômeno investigado na realidade onde ele acontece, elemento característico das investigações que adotam a abordagem qualitativa (BOGDAN; BIKLEN, 2004). Foi realizado um Estudo de Caso em escola privada da cidade de São Paulo, investigando a elaboração e aplicação de uma proposta pedagógica especialmente construída para estimular a formação de valores durante as aulas de Educação Física.

O projeto investigado foi proposto por uma professora que, ao perceber a dificuldade de seus alunos para respeitar as características dos colegas e resolver conflitos a partir do diálogo, decidiu construir formas de estimular a autonomia dos estudantes. Reconhecendo a interdependência entre ensino e pesquisa, apresentada em Freire (2004), esta professora optou por investigar a própria prática pedagógica, tornando-se uma das produtoras desta investigação. Além dela, também participaram do estudo 56 estudantes de duas turmas de $6^{\circ}$ ano do Ensino Fundamental, com idade entre 10 e 12 anos. Eles participaram da aplicação do projeto, que teve duração de 5 meses.

Para obter as informações necessárias foram utilizados como instrumentos a observação participante, o questionário e a entrevista. A observação participante foi executada pela própria professora e por outra pesquisadora. Ambas construíram notas de campo, com registros descritivos e analíticos (LAVILLE; DIONNE, 1999). Foram observadas 17 aulas de cada turma. Além da observação, foi aplicado um questionário aberto aos estudantes, para que eles pudessem expressar seu ponto de vista a respeito das atividades desenvolvidas. Foi realizada, ainda, uma entrevista com a professora, para identificar suas perspectivas sobre a proposta implementada. Notas de campo, questionário respondido pelos alunos e entrevista aberta (gravada e transcrita) foram analisados com a utilização da técnica de análise de 
conteúdo, seguindo orientações de Andrade (1999). Os procedimentos descritos foram aprovados por Comitê de Ética em Pesquisa, pelo responsável pela instituição, pelos estudantes e por seus responsáveis.

\section{A PROPOSTA PEDAGÓGICA: REFLEXÃO, DIÁLOGO E AUTOGESTÃo}

Puig (1998) explica que são elementos essenciais da autonomia o autoconhecimento, a compreensão crítica e a competência dialógica. Tomando como base as afirmações do autor a professora elaborou sua proposta pedagógica, selecionando propondo as seguintes expectativas de aprendizagem para seus alunos:

a) refletir sobre o relacionamento com os colegas e perceber suas próprias atitudes, bem como as atitudes adotadas pelos colegas, durante as aulas de Educação Física;

b) compreender a importância da existência de algumas regras para organizar a convivência no ambiente escolar ou fora dele;

c) ser capaz de propor e cumprir regras para convivência coletiva nas aulas de Educação Física;

d) dialogar sobre as diferenças entre as pessoas e a necessidade de respeitar características e convicções individuais.

É possível reconhecer semelhanças entre a proposição da professora e os objetivos apresentados por Hellison (2003) e por Siedentop (2002). Com base nessas expectativas, ela formulou seu plano de ensino, mantendo temas já definidos coletivamente durante o ano letivo. Handebol, atletismo e modalidades esportivas com raquetes foram alguns dos conteúdos tratados em aula. $\mathrm{O}$ conhecimento, a vivência e a transformação dessas atividades foi o pano de fundo para a discussão sobre a convivência humana dentro e fora das aulas de Educação Física. Diversos recursos foram empregados, procurando envolver os estudantes em reflexões sobre o comportamento dos colegas ou de familiares, assim como sobre seu próprio comportamento.

Durante as aulas, a organização das regras de convivência, o diálogo e a organização de jogos e suas regras passaram a ser conteúdo das aulas. Eles foram tratados intencionalmente e de forma planejada. Dessa forma, a professora procurou explicitar a natureza atitudinal dos conteúdos trabalhados, que geralmente permanecem ocultos no currículo (FREIRE et al., 2010; FREIRE, 2012).

\section{Construção coletiva das regras: Confecção do Painel}

Dentro da escola, um conjunto de regras define o comportamento a ser adotado por todos os envolvidos. Geralmente elas têm sido estabelecidas pelo professor ou por outras autoridades e são parte de uma moral escolar, capaz de influenciar o comportamento social dos estudantes, mesmo fora da instituição de ensino. Nessa perspectiva, a imposição de regras colabora para a formação de indivíduos heterônomos (THORNBERG, 2008).

A professora procurou trabalhar de forma diferente. Ela utilizou como ferramenta a construção de um painel, no qual os estudantes deveriam apresentar as regras que seriam adotadas nas aulas de Educação Física. Antes de iniciar a construção deste painel, a professora estimular a reflexão sobre a importância das regras. A princípio, procurou não apresentar sugestões ou ideias de condutas a serem seguidas, para não influenciar ou coagir seus alunos. 
Contudo, ao perceber que eles não apresentavam sugestões, decidiu tomar a iniciativa e propôs uma regra para que eles avaliassem se concordavam com ela. A reduzida participação dos estudantes, no início da atividade, pode ser motivada pela falta de oportunidade para tomar decisões. Na estrutura tradicional da escola, eles costumam acatar as normas estabelecidas (THORNBERG, 2008), sem possibilidade de questioná-las. Assim, envolve-los nas decisões possibilita o exercício de um novo comportamento, papel que deve ser exercido pela escola (FREIRE, 2004).

Algumas regras propostas já haviam sido combinadas no início do semestre letivo. Outras foram criadas durante a produção do painel. Para que a regra fosse aceita, alunos e professora-pesquisadora, tiveram que decidir juntos se a consideravam válida. Quando algum aluno discordava de uma determinada regra, era desencadeado um debate, momento em que todos teriam a oportunidade de expor seu ponto de vista.

Foi possível observar situações em que os estudantes, ao analisarem uma regra específica, questionavam sobre sua aplicabilidade fora do ambiente da Educação Física. Na quarta aula observada, por exemplo, quando discutiam a regra que envolvia a proibição no uso de palavras de baixo calão durante as aulas, alguns alunos argumentaram não compreender por que seus pais os proibiam de dizer tais palavras. Muitas vezes, elas eram pronunciadas por adultos e até mesmo pelos próprios pais. Questionando outra regra, alguns perguntaram por que deveriam fazer silêncio e prestar atenção quando outra pessoa está falando, mesmo quando o tema discutido não fosse considerado relevante. Dessa forma, foi possível perceber que os estudantes conseguiam relacionar as regras propostas nas aulas com aquelas presentes em seu cotidiano, tornando a atividade mais significante à medida que permitia conhecer e compreender sua realidade (FREIRE, 2004).

Fundamentando-se em Puig (1998) a professora incentivou os alunos a buscarem suas próprias respostas. Como afirma Menin (1996, p. 88) “[...] a autonomia exige que a sacralidade das leis, ou, em outro extremo, a arbitrariedade delas seja substituída pela racionalidade social: razões compartilhadas e coletivas justificam a criação das regras". Ao concluir a elaboração do painel, estudantes e professora assinaram o documento produzido coletivamente, ato que simbolizou o compromisso assumido por todos com o cumprimento das regras estabelecidas. A construção deste painel exercita a autorregulação dos estudantes (PUIG, 1998; PUIG et al., 2000).

Nas notas de campo elaboradas pela professora, foi descrita a percepção de algumas dificuldades enfrentadas durante a construção do painel. Ela explica que por vezes sentiu-se ansiosa pela construção das regras e teve que controlar seu desejo de impor algumas regras. Esta ansiedade, percebida pela professora, também foi relatada nas notas de campo elaboradas pela observadora. Durante uma das aulas, um aluno perguntou à professora se não haveria aula de Educação Física, uma vez que permaneciam em sala de aula. A professora respondeu ao estudante que haveria a aula, mas que precisaria de mais cinco minutos para concluir o trabalho com o painel. Ao responder desta forma, ela deixa de enfatizar que a construção do painel é parte da aula, que não acontece apenas em quadra. Assim, foi reforçada a crença criticada por Faria et al. (2010), na qual o envolvimento em discussões e reflexões sobre determinados temas diminui o já reduzido tempo destinado às aulas de Educação Física.

Esta dificuldade enfrentada pela professora pode estar presente também na realidade de outros professores. A resistência dos estudantes diante de uma aula que não envolva a prática motora pode ser percebida facilmente. Tal resistência talvez tenha origem na organização escolar que, tradicionalmente, limita a liberdade dos estudantes, obrigados a permanecer sentados durante horas. Sendo a Educação Física um das raras aulas que 
permitem aos alunos a possibilidade de se movimentar pela escola, ela é aguardada ansiosamente por eles. Obviamente, ao ter sua expectativa de movimento frustrada pela obrigatoriedade na permanência em sala, o aluno se manifesta, demonstrando insatisfação. A professora, entendendo esta realidade, também se incomoda ao notar que a permanência em sala frustra seus alunos.

Alguns estudantes destacam em suas respostas a percepção de que o trabalho com a construção de regras trouxe grande contribuição para as aulas realizadas. Abaixo, apresentamos alguns trechos dessas resposta:

Achei que a Educação Física melhorou muito, depois que o painel foi recolocado, porque a pessoa tem uma responsabilidade a mais exemplo: se alguém dá um soco em alguém a pessoa que levou não vai revidar mais a pessoa vai até o painel e mostra que a pessoa assinou e que ela não deve fazer isso.

[...] e o convívio entre as turmas melhorou também, melhorou a organização, foi tudo muito bom.

A professora também avalia de forma positiva o trabalho realizado, quando afirma em suas notas de campo que percebe:

[...] a ressonância positiva deste painel para o aluno mostrando que com as regras organizadas por eles e mais do que isso, assinadas por eles, houve uma demonstração de compromisso com as regras e com os demais colegas.

\section{Farol da Educação Física}

Outro recurso adotado nas aulas foi a construção de um "Farol da Educação Física", inspirado no método jornal-mural de Freinet (JIMENÉZ-ALEIXANDRE; PUIG 2012). Neste farol, fixado na parede lateral da quadra, ao lado do painel com as regras, foram organizados três momentos, com três cores diferentes: cor verde com o tema "eu felicito", cor amarela com o tema "eu proponho" e cor vermelha com o tema "eu critico". Os alunos, quando, como e se desejassem, poderiam colocar bilhetes com: felicitações à professora, aos colegas ou às aulas na cor verde; propostas de mudanças de condutas ou de atividades, na cor amarela; e críticas às aulas, às atividades ou às ações dos colegas ou da professora, na cor vermelha. Os bilhetes elaborados eram lidos pela professora e, nesse momento, realizava-se um debate sobre o conteúdo apresentado. Para estimular a participação dos estudantes na preparação dos bilhetes, a identificação do autores não era obrigatória. Esse Jornal-mural, continuou ainda na quadra até o final da intervenção.

É possível observar que, na construção e aplicação da proposta a professora procurou trabalhar também elementos essenciais para a construção da autonomia, apresentados por Puig (1998): a compreensão crítica e a competência dialógica. A compreensão crítica tem como finalidade principal compreender a complexidade das situações humanas. Ela não pode ser atingida por cada indivíduo isoladamente, mas é "[...] uma exigência que impõem os múltiplos pontos de vista distintos, que convergem e julgam os conflitos de valor" (PUIG, 1998, p. 86). Ela pode ser estimulada de diversas maneiras, como por exemplo, avaliando um fato verdadeiro que tenha acontecido no entorno dos envolvidos, analisando um caso fíctício, discutindo questões de um fato jornalístico ou dialogando a partir de um texto. No caso investigado, a compreensão crítica foi estimulada na análise e compreensão de situações que haviam acontecido durante as aulas de Educação Física. 
É difícil mensurar os resultados deste estímulo no comportamento dos estudantes, já que diversos fatores podem influencia-los (JONES, 2005). Porém, foi possível observar momentos em que alguns estudantes demonstraram ser competentes para compreender criticamente suas atitudes. Exemplo disso apareceu quando um estudante agrediu seu colega, culpando-o pela derrota da equipe a qual pertenciam. Em conversa privada (registrada pela professora em suas notas de campo) este aluno foi capaz de refletir sobre sua atitude e reconhecer seu erro, declarando que sempre tivera dificuldade em aceitar a derrota, pois fica bastante nervoso e acaba se descontrolando.

\section{Estímulo ao Diálogo}

A construção de uma compreensão crítica só será possível com o exercício da competência dialógica. Puig (1998, p. 26) ressalta que é preciso "[...] apreciar o diálogo como um dos valores essenciais para a educação moral e para a participação democrática". Este diálogo permitirá ao indivíduo expor seu ponto de vista e ouvir aos demais, podendo raciocinar sobre a sua própria opinião em confronto ou consoante a opinião de outrem, o que possibilita uma mudança de opinião.

Para estimular o diálogo foram realizadas discussões sobre regras e valores. Essas discussões aconteciam, principalmente, quando surgiam conflitos entre os estudantes. Foi possível observar diversos desentendimentos durante a organização dos grupos ou equipes para a participação em jogos. Durante a aplicação do projeto, a professora permitiu que os próprios estudantes formassem suas equipes, procurando oferecer oportunidade para que todos vivenciem a responsabilidade por esta escolha. Para Leitão et al. (2011) este tipo de atividade pode auxiliar a construção da autonomia nas aulas de Educação Física.

Contudo, ao acompanhar a estratégia adotada pela professora, a pesquisadoraobservadora relatou a presença de alguns problemas durante o processo adotado. Com certa frequência, os alunos menos habilidosos se negaram a assumir a responsabilidade pela formação das equipes. Em outros momentos, eles aceitaram a tarefa, mas se submetera aos desejos dos colegas, que insistiam na escolha de determinados alunos. A pesquisadora observou estudantes que, ao serem escolhidos, demonstraram descontentamento ou se recusaram a fazer parte de uma determinada equipe, seja por considerar que o grupo escolhido apresentava integrantes menos habilidosos, seja por ter desavenças pessoais com um determinado aluno.

De acordo com Puig et al. (2000), o educador não deve interferir nos grupos formados espontaneamente, mas deve auxiliar os educandos a conversarem a respeito dos problemas que permearam esses mesmos grupos. Nessa perspectiva, a professora participante procurou estimular a reflexão dos estudantes, questionando sobre o que sente o último a ser escolhido; sobre as dificuldades que alguns têm de se separar dos amigos durante os jogos; sobre o que deve acontecer com um aluno que não aceita participar de uma determinada equipe; ou sobre as relações entre competição e cooperação.

Em alguns momentos, a própria professora apontou problemas no comportamento dos estudantes e propôs soluções. Deste modo, em seu discurso acabou defendendo seus próprios valores, sem permitir que os alunos percebessem, por si mesmos, os problemas existentes nas aulas e tentassem solucioná-los, como propõe Tillman (2001). Percebendo a incoerência de sua atitude, ela declarou que teve dificuldade para deixar de estimular a heteronomia.

Outra dificuldade enfrentada, percebida pela professora e pela observadora, diz respeito à competência para envolver seus alunos nos debates realizados. Foi possível 
perceber que alguns alunos eram bastante participativos, apresentavam suas opiniões e sugestões, enquanto outros permaneciam sempre quietos, sem qualquer manifestação oral ou escrita. Em muitas aulas, procurava estimular esses estudantes, perguntando seu ponto de vista sobre determinado assunto. Alguns continuavam tímidos. Outros aproveitavam a oportunidade surgida. Diante desta dificuldade, era preciso diversificar as formas e momentos que permitissem a expressão das ideias dos alunos. O questionário aplicado na conclusão da proposta pode ser estratégia adotada pelos professores para conhecer a opinião dos estudantes que não se expressam verbalmente ou voluntariamente.

No discurso dos alunos é possível verificar a valorização do diálogo

A aula é bem divertida. A gente discute em grupo as coisas que a gente acha que tem de melhorar ou que todos não acharam legal... Eu acho isso bem legal, porque a gente interage bastante e discute em grupo.

[...] achei legal a professora discutir o que aconteceu na aula, no final da aula, porque muitas vezes na aula aconteciam problemas e não se resolviam. Ficávamos comentando na outra aula.

Apesar de gostarem das aulas de Educação Física e pedirem a realização de atividades motoras, percebe-se que os alunos apoiaram os momentos dedicados à reflexão e ao diálogo. Apoiaram, também, a possibilidade de participar das alterações propostas coletivamente. Parece que eles conseguiram perceber a relevância do diálogo nas relações sociais, nas quais a autoridade sobre as decisões não pertence a apenas uma pessoa, relevância esta destacada por Freire (2004) e Arantes (2007).

A partir do exposto, é possível perceber que reflexão, diálogo e tomada de decisão foram competências estimuladas na proposta pedagógica investigada, à semelhança do que acontece nos programas defendidos por Hellison (2003) e por Siedentop (2002). Outra similaridade percebida está na preocupação com a construção da responsabilidade entre os estudantes. No entanto, a proposta adotada pela professora se diferencia das demais, já que o esporte não foi o conteúdo exclusivo de suas aulas.

Podemos avaliar a proposta pedagógica aplicada a partir de diferentes perspectivas. Do pondo de vista dos estudantes, há uma percepção positiva, já que alguns deles declaram ver contribuições das aulas realizadas em seu cotidiano, como no trecho destacado a seguir

[...] Isto ajudou tanto na aula de Educação Física, como nas outras aulas e até fora do colégio, pois aprendemos que cada pessoa é bom e ruim em alguma coisa e temos que aprender a conviver com isso.

Contudo, esta percepção parece ingênua e precisa ser analisada de forma crítica. Durante a observação das aulas, foi possível constatar que o envolvimento dos estudantes não é homogêneo. Enquanto alguns participaram de forma ativa das propostas apresentadas, outros permaneciam em silêncio ou envolviam-se em conversas paralelas. Ao responder o questionário, sabendo que a professora faria a leitura, é possível que alguns deles tenham sentido dificuldades para expressar sua percepção real, e optaram por apresentar respostas que poderiam agrada-la.

A professora participante apresenta uma percepção diferente sobre os resultados da proposta adotada, apontando efeitos positivos e negativos. Inicialmente, ela declarou em suas notas de campo que os estudantes compreendiam os objetivos e a surpreendiam com seus 
discursos e atitudes. No entanto, durante a entrevista, relatou sentir-se frustrada ao ver que os alunos mantém atitudes de discriminação dos colegas e que parecem não entender o porquê de algumas atividades realizadas. Ela chega a questionar a importância da proposta aplicada.

Por um lado, as dúvidas e angústias expressas pela professora tornam evidente seu compromisso com a realização de um trabalho de boa qualidade, que exige constante questionamento e crítica. Por outro lado, ela parece ter formulado uma série de expectativas, nem sempre passíveis de concretização. Para Freire (2012) a criação dessas expectativas pode ser resultado de uma ilusão construída pelos professores de Educação Física, na tentativa de atribuir um sentido ao trabalho que realizam. É importante que o professor entenda que o aluno não constrói seus valores apenas nas aulas de Educação Física, mas a partir de uma série de experiências vividas nos mais diferentes contextos sociais (JONES, 2005). As atitudes dos amigos, dos pais, de atletas de destaque e de autoridades também são tomados como referência por esses alunos (CAMIRÉ; TRUDEL, 2010; JONES, 2008). Se o desenvolvimento da autonomia era o objetivo principal do programa, parece incoerente esperar que um comportamento determinado seja apresentado, já que é o estudante quem deve tomar suas decisões. Como ressalta Freire (2004) adotar a pedagogia da autonomia pressupõe o respeito à autonomia do aluno.

Assim, os professores devem compreender que "[...] a criança quando chega à escola já é portadora de uma vasta experiência, de uma história relativamente longa de formação que envolve não só conhecimentos, sensibilidades, mas também representações de valores, formas de julgamento e de comportamento" (GOERGEN, 2007, p. 747). Reconhecer esta realidade, desfazendo a ilusão construída é condição para que o professor identifique seus limites e possibilidades para estimular a construção de valores em seus alunos.

\section{CONSIDERAÇÕES FINAIS}

Preparar o estudante para a autonomia tem sido um dos objetivos defendidos por professores e pesquisadores, quando analisam o ensino da Educação Física na escola. Construir e avaliar caminhos que permitam a preparação do estudante autônomo é um desafio que merece ser investigado. Partindo desta premissa, o presente estudo foi realizado com a intenção de analisar a aplicação de uma proposta pedagógica para estimular a autonomia nas aulas de Educação Física e identificar a perspectiva de uma professora e de seus estudantes, diante da proposta aplicada.

A partir das observações realizadas e da aplicação de questionários e entrevistas foi possível verificar que o projeto aplicado permitiu que os objetivos propostos pela professora fossem atingidos. Em coerência com a literatura encontrada, a metodologia de ensino adotada permitiu que os estudantes exercitassem a tomada de decisão, o diálogo e a compreensão crítica, elementos essências da autonomia.

Entretanto, durante o processo de investigação foram identificadas algumas dificuldades enfrentadas pela professora. Uma delas envolveu a avaliação do envolvimento dos estudantes na confecção das normas, na elaboração do farol da Educação Física e nos diálogos estimulados pela professora. Desta forma, é importante que novos estudos sejam realizados, nos quais sejam utilizados recursos pedagógicos que permitam acompanhar a ação de um número maior de estudantes. Uma possibilidade é a criação de pequenos grupos para a discussão e proposição das regras. Outro recurso possível é a construção de um diário coletivo, no qual os próprios estudantes possam registrar a síntese dos trabalhos realizados e a apreciação crítica sobre a aula. 
Outras dificuldades enfrentadas pela professora foram percebidas durante a pesquisa, como o controle de sua ansiedade, a tendência ao autoritarismo e a construção de expectativas irreais. Investigar a presença dessas dificuldades no trabalho realizado por outros professores, que também busquem estimular a construção da autonomia em suas aulas, poderá trazer contribuições para que possamos compreender a origem dessas dificuldades e elaborar maneiras de superá-las.

\title{
THE CONSTRUCTION OF AUTONOMY IN PHYSICAL EDUCATION: IMPLEMENTATION AND EVALUATION OF A PEDAGOGICAL PROPOSAL
}

\begin{abstract}
The objective of this study was to analyze the use of a pedagogical project aimed stimulate the autonomy of students and to identify the vision of both teacher and students regarding the project. Observation, questionnaire and interview were the instruments used. The proposal applied stimulated the reflection, critical understanding and dialogue competence of students. However, it identified some difficulties faced by the teacher, as control of her anxiety, a tendency to authoritarianism and unrealistic expectations. Furthermore, the assessment of students' involvement needs improvement. New research may help to understand the origin and ways to overcome difficulties.
\end{abstract}

Keywords: Physical Education and Training. Autonomy. Social Values.

\section{LA CONSTRUCCIÓN DE LA AUTONOMÍA EN EDUCACIÓN FÍSICA: APLICACIÓN Y EVALUACIÓN DE UNA PROPUESTA PEDAGÓGICA}

\section{Resumen}

El objetivo de este estudio fue analizar la aplicación de un proyecto pedagógico para estimular la autonomía de los estudiantes y identificar la visión del profesor y los alumnos a cerca del proyecto. Observación, cuestionario y entrevista fueron los instrumentos utilizados. La propuesta estimuló la reflexión, la comprensión crítica y la competencia para el diálogo de los estudiantes. Fueran identificadas algunas dificultades enfrentadas por la maestra, como el control de su ansiedad, una tendencia al autoritarismo y expectativas poco realistas. Por otra parte, la evaluación de la participación de los estudiantes necesita mejoras. Nuevas investigaciones pueden ayudar a entender el origen y la manera de superar las dificultades.

Palabras clave: Educación y Entrenamiento Físico. Autonomía. Valores Sociales.

\section{REFERÊNCIAS}

ANDRADE, M. M. Introdução à metodologia do trabalho científico. 4. ed. São Paulo: Atlas, 1999.

ARANTES, V. A. A construção social e psicológica dos valores. In: ARANTES, V. A. Educação e valores: pontos e contrapontos. São Paulo: Summus, 2007.

BAILEY, R. et al. The educational benefits claimed for physical education and school sport: an academic review. Research Papers in Education, v. 24, n. 1, p. 1-27, 2009. 
BENSON, P. Autonomy in language teaching and learning. Language Teaching, v. 40, n. 1, p. 21-40, 2007.

BOGDAN, R. C.; BIKLEN, S. Investigação Qualitativa em Educação: uma introdução à teoria e aos métodos. Porto: Porto Editora, 2004.

CABALLERO-BLANCO, P.; DELGADO-NOGUERA, M. A.; ESCARTÍ-CARBONELL, A. Analysis of Teaching Personal and Social Responsibility model-based programmes applied in USA an Spain. Journal of Human Sport and Exercise, v. 8, n. 2, p. 427-441, 2013.

CAMIRE, M.; TRUDEL, P. High school athletes $\square$ perspectives on character development through sport participation. Physical Education and Sport Pedagogy, v. 15, n. 2, p. 193-207, 2010 .

CAMIRE, M.; TRUDEL, P.; BERNARD, D. A case study of a high school sport program designed to teach athletes life skills and values. Sport Psychologist, v. 27, p. 188-200, 2013.

FARIA, B.A. et al. Inovação Pedagógica na Educação Física: o que aprender com práticas bem sucedidas? Ágora para la EF y el deporte, v. 12, n. 1, p. 11-28, 2010.

FREIRE, E. S. A construção de valores nas aulas de Educação Física: habitus e illusio no cotidiano de três professoras. 2012, 186f. Tese (Doutorado em Educação Física) Programa de Pós Graduação em Educação Física, Universidade São Judas Tadeu, São Paulo, 2012.

FREIRE, E. S. et al. A Dimensão Atitudinal nas aulas de Educação Física: conteúdos selecionados pelos professores. Revista de Educação Física/UEM, Maringá, v. 21, n. 2, 2010.

FREIRE, E. S.; MIRANDA, M. L. J. The production of knowledge about the building of values in physical education at school: methods, methodology and epistemology. Physical Education and Sport Pedagogy, v. 19, n. 1, p. 35-47, 2014.

FREIRE, P. Pedagogia da autonomia: saberes necessários à prática educativa. 30.ed. São Paulo: Paz e Terra, 2004.

GOERGEN, P. Educação moral hoje: cenários, perspectivas e perplexidades. Educação e Sociedade, $\quad$ v. $28, \quad$ n. $100, \quad 2007 . \quad$ Disponível em: http://www.scielo.br/pdf/es/v28n100/a0628100.pdf Acesso em: 20 jul 2010.

HELLISON, D. Teaching personal and social responsibility in physical education. In: SILVERMAN, S.J. \& ENNIS, C.D. (eds.) Students learning in physical education: Applying research to enhance instruction. Champaign, IL: Human Kinetics, 2003. p. 241-254.

HELLISON, D.; WALSH, D. Responsibility-Based youth programs evaluation: investigating the investigations. Quest, v. 54, p. 292-307, 2002.

JIMÉNEZ-ALEIXANDRE, M. P.; PUIG, B. Argumentation, evidence evaluation and critical thinking. In: FRASER, B.; TOBIN, K.; MCROBBIE, C. (Eds.), Second International Handbook of Science Education, 2012. p. 1001-1015. 
JONES, C. Teaching virtue through physical education: some comments and reflections. Sport, Education and Society, v. 13, n. 3, p. 337-349, 2008.

JONES, C. Character, virtue and physical education. European Physical Education Review, v.11, n.2, p.139-151, 2005.

KIRK, D. Sport Education, Critical Pedagogy, and Learning Theory: Toward an Intrinsic Justification for Physical Education and Youth Sport. Quest, v. 58, p. 255-264 , 2006.

LA TAILLE, Y. A importância da generosidade no início da gênese da moralidade na criança. Psicologia: Reflexão e Crítica, v. 19, n. 1, p. 09-17, 2006.

LAVILLE, C.; DIONNE, J. A construção do saber: manual de metodologia da pesquisa em ciências humanas. Porto Alegre: Artmed, 1999. 340 p.

LEITÃO, M. C. et al. Implicações sociais e autonomia em educação física escolar: uma abordagem construtivista do movimento. Revista Brasileira de Ciência e Movimento, v. 19, n. 3, p. 76-85, 2011.

MENIN, M. S. S. Desenvolvimento moral: Refletindo com pais e professores. In: MACEDO, L. de (org.). Cinco estudos de Educação Moral. São Paulo: Casa do Psicólogo, 1996.

O'DONOVAN, T. M.; MACPHAIL, A.; KIRK, D. Active citizenship through sport education. Education 3-13, v. 38, n. 2, p. 203-215, 2010.

PARO, V. H. Autonomia do educando na escola fundamental: um tema negligenciado. Educar em Revista, n. 41, p. 197-213, 2011.

PUIG, J. M. Ética e Valores: métodos para um ensino transversal. São Paulo: Casa do Psicólogo, 1998.

PUIG, J. M. et al. Democracia e Participação escolar: propostas de atividades. São Paulo: Moderna, 2000.

SIEDENTOP, D. Sport Education: a retrospective. Journal of teaching in Physical Education, v. 21, p. 409-418, 2002.

THORNBERG, R. The lack of professional knowledge in values education. Teaching and Teacher Education, v. 24, n. 7, p. 1791-1798, 2008.

TILLMAN, D. Atividades com valores para estudantes de 7 a 14 anos. São Paulo: Editora Confluência, 2001.

VIDONI, C.; WARD, P. Effects of Fair Play Instruction on student social skills during a middle school Sport Education unit. Physical Education and Sport Pedagogy, v. 14, n. 3, p. 285-310, 2009. 
WALSH, S.; OZAETA, J.; WRIGHT, P. M. Transference of responsibility model goals to the school environment: exploring the impact $f$ a coaching club program. Physical Education and Sport Pedagogy, v. 15, n. 1, p. 15-28, 2010.

Recebido em: 26/04/2015

Revisado em: 12/08/2015

Aprovado em: 31/08/2015

Endereço para correspondência:

Elisabete dos Santos Freire

elisabetefreire@uol.com.br

Universidade São Judas Tadeu

Av. Vital Brasil, 1000

Butantã, São Paulo - SP, 05503-001 